\title{
Postoperative radiotherapy with or without concurrent chemotherapy for oral squamous cell carcinoma in patients with three or more minor risk factors: a propensity score matching analysis
}

\author{
Kang-Hsing Fan ${ }^{1,7}$, Yen-Chao Chen ${ }^{2}$, Chien-Yu Lin ${ }^{1,6}$, Chung-Jan Kang ${ }^{4}$, Li-Yu Lee ${ }^{5}$, Shiang-Fu Huang ${ }^{4,6}$, \\ Chun-Ta Liao ${ }^{4}$, Shu-Hang Ng${ }^{6}$, Hung-Ming Wang ${ }^{3,8}$ and Joseph Tung-Chieh Chang ${ }^{1,8,9^{*}}$ (D)
}

\begin{abstract}
Background: To investigate the advantage of concurrent chemotherapy with postoperative radiotherapy (RT) of oral squamous cell carcinoma (OSCC) in patients with three or more minor risk factors.

Methods: Minor risk factors included pT4 disease, pN1 disease, margin $\leq 4 \mathrm{~mm}$, poor differentiation, perineural invasion, vessel or lymphatic invasion, and tumor invasion depth $\geq 11 \mathrm{~mm}$. Surgery was the primary treatment, followed by RT or concurrent chemoradiation (CCRT). After propensity score matching, 34 patients in each treatment group were selected for comparison.
\end{abstract}

Results: The median follow-up for living patients was 86.4 months (range: 47-189 months). The 5-year overall survival of the RT and CCRT groups was $35.3 \%$ and $67.2 \%(p=0.018)$, respectively. The 5 -year recurrence-free survival of the RT group and CCRT group was $42.6 \%$ and $75.4 \%(p<0.01)$.

Conclusion: Postoperative CCRT for patients with three or more minor risk factors increased recurrence-free and overall survival.

Keywords: Head and neck cancer, Oral cavity cancer, Radiotherapy, Concurrent chemotherapy, Postoperative radiotherapy

\section{Background}

Treatment for advanced head and neck cancer typically includes a combination of different modalities. For patients who undergo surgery, adjuvant radiotherapy (RT) can reduce the risk of tumor recurrence when advanced features are noted [1-3]. The presence of nodal metastasis with extracapsular spreading and positive surgical margins are clear indications for postoperative radiotherapy (PORT) with concurrent chemotherapy $[4,5]$. However,

\footnotetext{
* Correspondence: cgmhnog@gmail.com; jtchang@adm.cgmh.org.tw 'Department of Radiation Oncology, Chang Gung Memorial Hospital at LinKou, Taoyuan, Taiwan

${ }^{8}$ Department of Medicine, School of Medicine, Chang Gung University, Taoyuan, Taiwan

Full list of author information is available at the end of the article
}

our previous study showed that the presence of three or more minor risk factors in pathological samples of oral squamous cell carcinoma (OSCC) was correlated with an inferior outcome after surgery and PORT. These minor risk factors include T4 disease, pathological N1 disease, a surgical margin $\leq 4 \mathrm{~mm}$, poor differentiation, perineural invasion, vessel invasion, lymph invasion, and tumor invasion depth $\geq 11 \mathrm{~mm}$. Tumor recurrence was increased compared with that in the control arms of the two randomized studies cited above [4-6]. Our previous study was based on the notion of risk accumulation, and other studies have also considered risk accumulation. Parsons et al. found that the number of indications for PORT was a predictor of locoregional recurrence for head and neck cancer [7]. Therefore, it is reasonable to hypothesize that 
the presence of multiple risk factors indicates the need for more intensive treatment. Thus, patients with three or more risk factors were directed to undergo postoperative concurrent chemoradiation (CCRT) after 2007. The present study was undertaken to analyze the treatment results.

\section{Methods}

With the permission of the institutional review board, we retrieved clinical data on OSCC patients with three or more minor risk factors from the cancer registry from 1999 to 2009. After reviewing medical records and tumor board discussion records, 109 patients were selected. The exclusion criteria included the presence of (or no information regarding) positive resection margins, the presence of (or no information regarding) extracapsular spreading in metastatic nodes, a history of previous cancer, a second synchronous cancer, no standard neck dissection (at least supraomohyoid dissection), or any contraindication for CCRT recorded in the tumor board discussion. Tumor staging was based on the pathology findings and revised according to the 7th edition of the American Joint Committee on Cancer (AJCC) staging system [8].

All characteristics and treatment parameters were reviewed and recorded. Anemia was defined by hospital standard (hemoglobin $<13.5 \mathrm{~g} / \mathrm{dL}$ in male and $<12 \mathrm{~g} / \mathrm{dL}$ in female). Propensity-score matching was performed to reduce bias. R Statistical Software (version 3.2.4; R Foundation for Statistical Computing, Vienna, Austria) was used with Matchit package, and matching method was nearest-neighbor with 1 to 1 matching. Patients were divided into 2 group according to treatment method (postoperative RT or CCRT), 34 patients in each treatment group (RT and CCRT groups) were selected.

All patients received postoperative radiotherapy consisting of a conventional fractionated dose of 1.8 or $2 \mathrm{~Gy}$ at one fraction per day 5 days per week. A 6-MV photon beam was used for a total dose of 60 to 66 Gy. The initial treatment volume included the primary tumor bed with general margins and the regional cervical lymph nodes. Some patients received PORT by conventional field arrangement, which included a bilateral opposing field and a low anterior portal. The spinal cord was shielded after 46 to 46.8 Gy was delivered. Then, posterior and lower cervical lymph nodes were irradiated by an electron beam if necessary. Other patients received PORT by 3-dimensional conformal radiation therapy (3DCRT) or intensity modulation radiation therapy (IMRT). The dose delivered to the spinal cord and brain stem was limited to $50 \mathrm{~Gy}$. Without violation of constraints for the brain stem and spinal cord, $95 \%$ of the clinical tumor volume and $90 \%$ of the planning treatment volume should be irradiated at $100 \%$ of the prescribed dose. After the administration of 46 to $50 \mathrm{~Gy}$, the treatment area was reduced such that only the tumor bed and regions with metastatic nodes were irradiated.

Concurrent chemotherapy was cisplatin-based and was administered at either a low or high dose. For lowdose cisplatin, the prescribed dose was 40 to $50 \mathrm{mg} / \mathrm{m}^{2}$ administered every week or every other week, with or without an additional oral 5-fluorouracil prodrug $[9,10]$. For high-dose cisplatin, the prescribed dose was $100 \mathrm{mg} / \mathrm{m}^{2}$ administered every 3 weeks. High-dose chemotherapy was typically administered to patients for two to three cycles, whereas low-dose chemotherapy was administered for four to six cycles.

The outcome measures included locoregional recurrence, distant metastasis, second primary cancer, and death. A re-staging study in patients with a recurrent tumor or a second primary cancer was used to define the tumor extension. Salvage treatment or best supportive care was given depending on the status of the disease and the patient. If a death occurred, the cause was reviewed in detail. Recurrence or a second primary cancer was verified by pathological examination or consequent clinical findings if no tissue was available. Second primary cancers and death unrelated to recurrence or complications were not considered treatment failure. The primary end points were death and tumor recurrence, and the secondary end points were locoregional recurrence and a second primary cancer. Survival was calculated from the date of radical surgery to the date of the event, which was defined as tumor recurrence or "death from disease" for recurrence-free survival (RFS) and death for overall survival (OS). Locoregional recurrence was defined as the event for locoregional recurrence-free survival (LRRFS). We used the KaplanMeier method for survival analysis and the log-rank test to determine whether there were significant differences between the patients with respect to the end points. The Cox regression model was used to perform the multivariate analysis. Correlations of each variable with the end points were evaluated by both univariate and multivariate analyses. Differences were considered significant when the $p$-value was $<0.05$. The commercial statistics package PASW Statistics 18 (SPSS Inc., Chicago, IL) was used for the statistical analysis.

\section{Results}

\section{Patient population}

The patient ages ranged from 33 to 70 years, with a median of 53 years. A total of $60(88.2 \%)$ patients were male, and eight (11.8\%) patients were female. The most common subsite was the buccal mucosa $(26,38.3 \%)$, followed by the tongue $(16,23.5 \%)$, gums $(15,22.1 \%)$, retromolar trigone $(8,11.8 \%)$, mouth floor $(2,2.9 \%)$, and hard palate (one, 1.5\%). A total of 3 (4.4\%), 15 (22.1\%), 7 
$(10.3 \%)$, and $43(63.3 \%)$ patients had pathological stage $\mathrm{T} 1, \mathrm{~T} 2, \mathrm{~T} 3$, and $\mathrm{T} 4$ disease, respectively, and 27 (39.7\%) patients had pathological N1 nodal metastasis. Table 1 lists the characteristics of all patients after propensity score matching. The differences between the CCRT and RT groups were not significant, with the exception of a greater number of patients with pathological N1 stage in the CCRT group $(p=0.046)$.

\section{Radiotherapy and chemotherapy}

A total of $42(61.8 \%)$ patients began PORT within 6 weeks after radical surgery, and 61 (89.7\%) patients completed PORT within 8 weeks. PORT was performed in $30(44.1 \%)$ patients using the IMRT technique. One patient did not complete the entire radiotherapy course. This patient received CCRT and was the only patient who died from adverse events. A total of 23 (33.8\%) patients received a total PORT dose of $66 \mathrm{~Gy}$, and the other patients received a total dose of at least 60 but less than 66 Gy. In the CCRT group, $6(8.8 \%)$ patients did not receive the desired cisplatin dose $\left(200 \mathrm{mg} / \mathrm{m}^{2}\right)$. Details of treatment-related variables of the RT and CCRT groups are listed in Table 2. Because the CCRT group was a modern cohort, IMRT was significantly more common in this group. Differences in other variables were reduced to insignificance after matching.

\section{Overall survival}

At the time of the analysis, 41 patients had died. The cause of death was cancer recurrence in 26 cases, treatment-related adverse events in one case (pneumonia), a second primary cancer in 11 cases, and non-cancer disease in 3 cases. The median follow-up time among survivors were 130 months and 86 months for RT group and CCRT group, respectively. The 5 -year OS rate was $51.2 \%$, and the median survival was 59 months. The median survival of the CCRT and RT group were 79.5 months and 33 months, respectively. The 5 -year OS rates of the CCRT and RT group were 67.2 and $35.3 \%$, respectively $(p=0.02$, Fig. 1). In the univariate analysis, the absence of chemotherapy and presence of anemia were correlated with poor OS $(p<0.05$, Table 3$)$. In the multivariate analysis, betel quid chewing, anemia, tumor invasion depth $\geq 11 \mathrm{~mm}$, and concurrent chemotherapy were independent prognostic factors for OS $(p<0.05$, Table 4$)$.

\section{Recurrence-free survival}

A total of 30 patients had documented disease recurrence. The 5-year RFS rate of all patients was $57.7 \%$. Local recurrence (16) was the most common first recurrence pattern, followed by nodal (6), distant (4), both local and regional (1), and local/regional/distant all together (1). Four patients were salvaged by surgery and/ or radiotherapy. The CCRT group had a significantly higher 5-year RFS rate than the RT group $(75.4 \%$ vs. $42.6 \%, p<0.01$, Fig. 2). The absence of chemotherapy and poorly differentiated histology were significantly correlated with poor RFS $(p<0.05)$ in the univariate analysis (Table 3). In the multivariate analysis, tumor invasion depth $\geq 11 \mathrm{~mm}$, pathological T4 disease, interval between surgery and PORT of more than 6 weeks, concurrent chemotherapy, and a habit of betel quid chewing were independent poor prognostic factors $(p<0.05$, Table 4$)$.

\section{Lethal adverse events, second primary cancers, and other death events}

One patient died from acute adverse events. The mortality rate was $2.8 \%$ among patients who received CCRT. Fifteen patients developed second primary cancers during the follow-up period. Head and neck cancers were the most common type and occurred in 9 patients. Additionally, 2 patients developed lung cancer, 2 developed esophageal cancer, one developed prostate cancer, and one developed acute myelocytic leukemia during the follow-up period. Eight and 7 patients in the CCRT and RT groups, respectively, developed a second primary cancer, and the risk of developing a second primary cancer was similar between the two groups (chi-square test, two-tailed, $p=0.9$ ).

\section{Discussion}

Radiotherapy is an important treatment for head and neck cancers. Indications for PORT are based on specific findings obtained from pathology samples. Clinical trials have confirmed the role of postoperative CCRT in the treatment of head and neck cancers with positive resection margins or lymph node metastases with extracapsular spreading $[4,5]$. However, according to previous studies, a higher tumor recurrence rate is also associated with the presence of three or more risk factors other than a positive resection margin or extracapsular spreading [6]. Since this finding, a shift in the treatment protocol from RT to CCRT was proposed. Fortunately, as demonstrated in the current study, the treatment result was significantly improved by CCRT.

Various methods are used to classify the risk recurrence and assign the appropriate treatment for head and neck cancer. Dominant prognostic factors, such as a positive resection margin and extracapsular spread, can indicate the need for a different treatment. Additionally, developing a prediction model or a nomogram using multiple prognostic factors can serve as another method [11]. Risk factor clustering is another means by which tumor recurrence risks can be classified. The presence of a greater number of risk factors correlates with an increased risk of tumor recurrence in retrospective analyses [7, 12]. A randomized trial of dose escalation for head and neck cancer also found that the risk of tumor 
Table 1 Characteristics of all patients

\begin{tabular}{llll}
\hline Characteristic & $\begin{array}{l}\text { Frequency in the } \\
\text { CCRT group (\%) }\end{array}$ & $\begin{array}{l}\text { Frequency in the } \\
\text { RT group (\%) }\end{array}$ & $\begin{array}{l}p \text {-value } \\
(2 \text {-sided) }\end{array}$ \\
\hline Sex & & & \\
Male & $28(82.4 \%)$ & $32(94.1 \%)$ & 0.259 \\
Female & $6(17.6 \%)$ & $2(5.9 \%)$ & \\
$\begin{array}{lll}\text { ECOG performance } \\
0-1\end{array}$ & $33(97.1 \%)$ & $32(94.1 \%)$ & 1 \\
2 & $1(2.9 \%)$ & $2(5.9 \%)$ & \\
Age & & & $1(2.9 \%)$ \\
$<40$ years & $2(5.9 \%)$ & $33(97.1 \%)$ & 1 \\
$\geqq 40$ years & $32(94.1 \%)$ &
\end{tabular}

Other comorbidities

$\begin{array}{cll}\text { No } & 19(55.9 \%) & 26(76.5 \%) \\ \text { Yes } & 15(44.1 \%) & 8(23.5 \%) \\ \text { Smoking } & & \\ \text { Yes } & 27(79.4 \%) & 29(85.3 \%) \\ \text { No } & 7(20.6 \%) & 5(24.6 \%) \\ \text { Alcohol } & & \\ \text { Yes } & 25(73.5 \%) & 27(79.4 \%) \\ \text { No } & 9(26.5 \%) & 7(20.6 \%)\end{array}$

Betel quid

$\begin{array}{lll}\text { Yes } & 21(61.8 \%) & 26(76.5 \%) \\ \text { No } & 13(38.2 \%) & 8(23.5 \%)\end{array}$

Anemia

Yes

No

Site $^{a}$

Tongue

Mouth floor

Buccal mucosa

Gums

Hard palate

Retromolar trigone

$10(29.4 \%)$

$10(29.4 \%)$

$24(70.6 \%)$

$24(70.6 \%)$

9 (26.5\%)

7 (20.6\%)

$1(2.9 \%)$

$1(2.9 \%)$

$12(35.3)$

8 (23.5\%)

$14(41.2 \%)$

$7(20.6 \%)$

0

$5(14.7 \%)$

Differentiation

Other

Poor

Pathologic T stage

$\mathrm{T} 1-3$
$\mathrm{~T} 4$

Pathologic N stage

$\begin{array}{lll}\text { N0 } & 16(47.1 \%) & 25(73.5 \%) \\ \text { N1 } & 18(52.9 \%) & 9(26.5 \%)\end{array}$

Margin distance

$\begin{array}{lll}<5 \mathrm{~mm} & 19(55.9 \%) & 24(70.6 \%) \\ \geq 5 \mathrm{~mm} & 15(44.1 \%) & 10(29.4 \%)\end{array}$

0.294
Table 1 Characteristics of all patients (Continued)

\begin{tabular}{|c|c|c|c|}
\hline Characteristic & $\begin{array}{l}\text { Frequency in the } \\
\text { CCRT group (\%) }\end{array}$ & $\begin{array}{l}\text { Frequency in the } \\
\text { RT group (\%) }\end{array}$ & $\begin{array}{l}\text { p-value } \\
\text { (2-sided) }\end{array}$ \\
\hline \multicolumn{4}{|l|}{ Skin invasion } \\
\hline Yes & $6(17.6 \%)$ & $9(26.5 \%)$ & \multirow[t]{2}{*}{0.56} \\
\hline No & $28(82.4 \%)$ & $25(73.5 \%)$ & \\
\hline \multicolumn{4}{|l|}{ Bone invasion } \\
\hline Yes & $14(41.2 \%)$ & $16(47.1 \%)$ & \multirow[t]{2}{*}{0.807} \\
\hline No & $20(58.8 \%)$ & $18(52.9 \%)$ & \\
\hline \multicolumn{4}{|c|}{ Perineural invasion } \\
\hline Yes & $21(61.8 \%)$ & $22(64.7 \%)$ & \multirow[t]{2}{*}{1} \\
\hline No & $13(38.2 \%)$ & $12(35.3 \%)$ & \\
\hline \multicolumn{4}{|c|}{ Vascular invasion } \\
\hline Yes & $4(11.8 \%)$ & $1(2.9 \%)$ & \multirow[t]{2}{*}{0.356} \\
\hline No & 30 (88.2\%) & $33(97.1 \%)$ & \\
\hline \multicolumn{4}{|c|}{ Lymphatic invasion } \\
\hline Yes & $1(2.9 \%)$ & $1(2.9 \%)$ & \multirow[t]{2}{*}{1} \\
\hline No & $33(97.1 \%)$ & $33(97.1 \%)$ & \\
\hline \multicolumn{4}{|c|}{ Invasion depth of tumor } \\
\hline$<10 \mathrm{~mm}$ & $5(24.6 \%)$ & $2(5.9 \%)$ & \multirow[t]{2}{*}{0.427} \\
\hline$\geq 10$ & $29(75.4 \%)$ & $32(94.1 \%)$ & \\
\hline
\end{tabular}

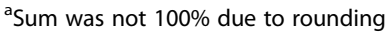

Abbreviations: $R T$ radiotherapy, CCRT concurrent chemoradiation

recurrence increased with the clustering of two or more prognostic factors [13]. Our previous study showed the same result in OSCC while excluding disease with positive resection margin or extracapsular spread. Thus, clustering of 3 or more minor risk factors is an indication of a higher tumor recurrence risk. The present study took a step further to review the results of a new treatment protocol.

Table 2 Treatment variables of all patients

\begin{tabular}{|c|c|c|c|}
\hline Characteristic & CCRT group (\%) & RT group (\%) & $p$-value \\
\hline \multicolumn{4}{|l|}{ RT technique } \\
\hline Other & $13(38.2 \%)$ & $25(73.5 \%)$ & \multirow[t]{2}{*}{$<0.01^{*}$} \\
\hline IMRT & $21(61.8 \%)$ & $9(26.5 \%)$ & \\
\hline \multicolumn{4}{|c|}{ RT duration (days) } \\
\hline$\leq 8$ weeks & $32(94.1 \%)$ & $29(85.3 \%)$ & \multirow[t]{2}{*}{0.427} \\
\hline$>8$ weeks & $2(5.9 \%)$ & $5(24.7 \%)$ & \\
\hline \multicolumn{4}{|c|}{ Time between OP \& RT } \\
\hline$\leq 6$ weeks & $20(58.8 \%)$ & $22(64.7 \%)$ & \multirow[t]{2}{*}{0.803} \\
\hline$>6$ weeks & $14(41.2 \%)$ & $12(35.3 \%)$ & \\
\hline \multicolumn{4}{|l|}{ RT dose } \\
\hline$<6600$ cGy & $20(58.8 \%)$ & $25(73.5 \%)$ & \multirow[t]{2}{*}{0.305} \\
\hline 6600 cGy & $14(41.2 \%)$ & 9 (26.5\%) & \\
\hline
\end{tabular}

*Significant difference, $p<0.05$

Abbreviations: $R T$ radiotherapy, IMRT intensity-modulated radiotherapy, $O P$ operation, CCRT concurrent chemoradiation 


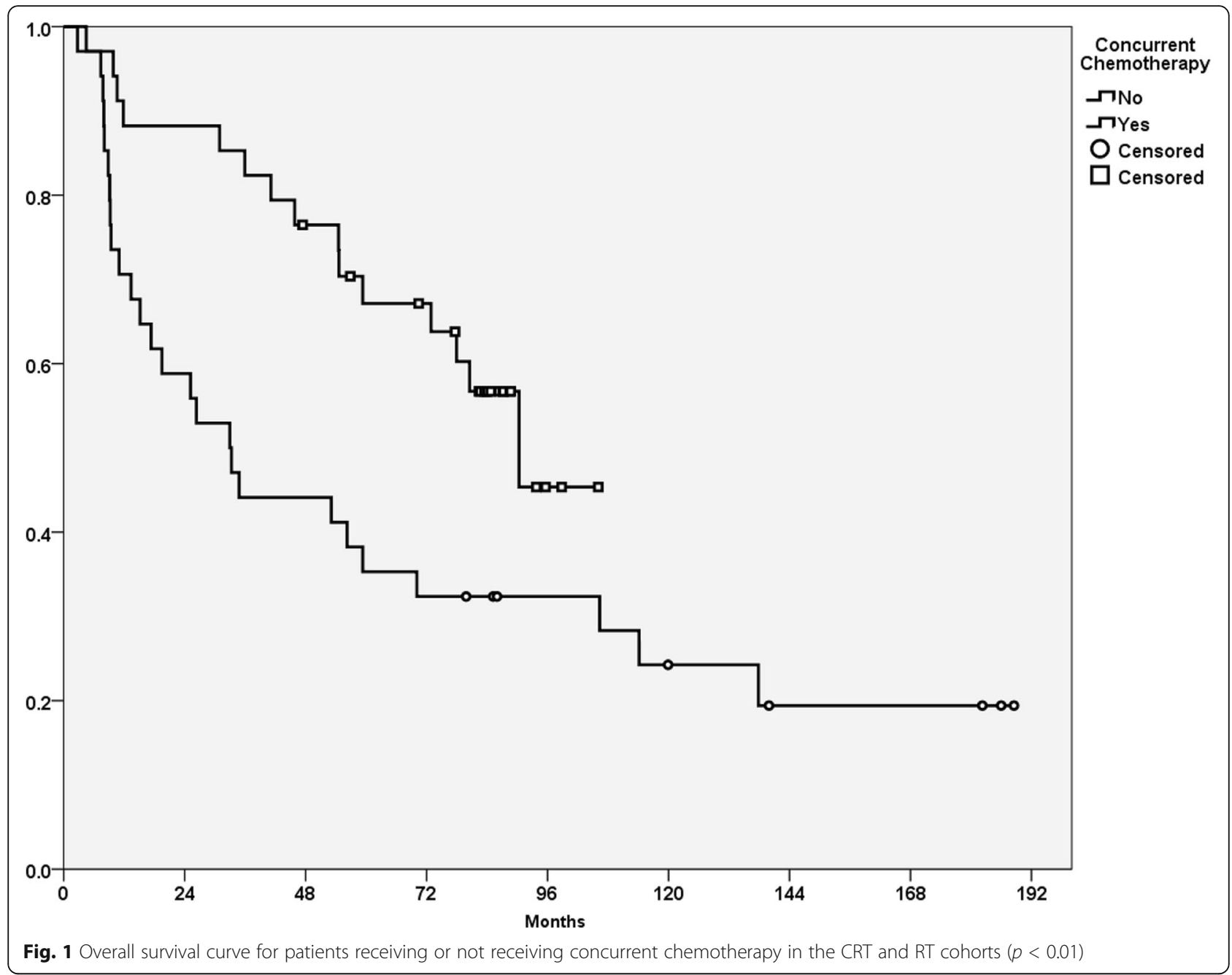

The use of CCRT to improve the treatment outcome of OSCC patients presenting with three or more minor risk factors is reasonable. CCRT reduces the risk of death from head and neck cancer, [14] and randomized trials have demonstrated that concurrent chemotherapy reduces locoregional recurrence rather than distant metastasis $[4,5]$ A previous study examining the effect of three or more minor risk factors reported that only $4 \%$ of all cases of first tumor recurrence involved distant metastasis [6]. Due to the high probability of locoregional recurrence, CCRT is likely to be beneficial. The current study revealed that CCRT greatly improves the outcomes of OSCC patients with three or more minor risk factors.

In the OS analysis, betel quid chewing was correlated with a lower OS. It was not the traditional prognostic factor which is related to treatment variables or disease status. Betel quid is a strong OSCC carcinogen [15]. It is reasonable that betel quid chewing was correlated with more death events when 11 of 41 deaths were caused by a second primary cancer, and OSCC was the most common second primary cancer in this cohort.

Since treatment principle was changed with time and this study included patients from a long period of time, treatment techniques were different between groups and some clinical information was not available. In CCRT group, IMRT were more commonly used, and the median follow-up period among survivors was shorter. The data of human papillomavirus (HPV) prevalence was lacking in most of patients. Currently, IMRT has been approved that it significantly reduces the risk of toxicities for patients with head and neck cancer. But the benefit of better tumor control was only shown in radiotherapy for nasopharyngeal cancer [16]. Two randomized trials targeting head and neck cancer did not show any benefit from IMRT in tumor control and overall survival $[17,18]$. Therefore, we believe that most of improvement in cancer control still came from concurrent chemotherapy. Although HPV status were unknown in most of the patients, but the role of HPV infection in 
Table 3 Overall and recurrence-free survival according to patient characteristics and treatment variables

\begin{tabular}{lll}
\hline Characteristic & $\begin{array}{l}\text { 5-year overall survival } \\
(p \text {-value) }\end{array}$ & $\begin{array}{l}\text { 5-year recurrence- } \\
\text { free survival }\end{array}$ \\
\hline Sex & & \\
Male & $51.4 \%(0.539)$ & $56.7 \%(0.826)$ \\
Female & $50 \%$ & $75 \%$ \\
Age & &
\end{tabular}

$$
<40 \text { years }
$$$$
100 \%(0.136)
$$$$
\geqq 40 \text { years }
$$$$
49.1 \%
$$

100\% (0.19)

Smoking

Yes

No

$51.5 \%(0.536)$

$50 \%$

Alcohol

Yes

No

Betel quid

$\begin{array}{ll}\text { Yes } & 42.2 \%(0.068) \\ \text { No } & 71.1 \% \\ \text { Anemia } & \\ \text { Yes } & 29.2 \%(0.002)^{*} \\ \text { No } & 60.2 \%\end{array}$

Differentiation

$\begin{array}{ll}\text { Poor } & 40 \%(0.752) \\ \text { Well or moderate } & 53.1 \% \\ \text { PT stage } & \\ \text { PT4 } & 52.9 \%(0.978) \\ \text { PT1-3 } & 48 \%\end{array}$

pN stage

N1

Surgical margin

$$
\begin{aligned}
& \leq 4 \mathrm{~mm} \\
& >4 \mathrm{~mm}
\end{aligned}
$$

Skin invasion

$$
\text { Yes }
$$

No

Bone invasion

Yes

No

Perineural invasion

$$
\text { Yes }
$$

No

Vascular invasion

Yes

No
$55.5 \%(0.311)$

$$
35.7 \%
$$

$48 \%$

$55.3 \%(0.481)$

$48.4 \%$

$48.2 \%(0.791)$

$56 \%$

$59.3 \%(0.485)$

$48.9 \%$

$46.4 \%(0.44)$

$55 \%$

$51.2 \%(0.953)$

$50.2 \%$

$60 \%(0.444)$

$48.8 \%$
$56.9 \%$

$57.2 \%(0.91)$

$66.7 \%$

$57.6 \%(0.575)$

$72.7 \%$

$50.8 \%(0.154)$

$75.9 \%$

54\% (0.106)

$61 \%$

$30 \%(0.03)^{*}$

$64 \%$

64\% (0.461)

$50 \%$

$62.7 \%(0.34)$

$53.8 \%$

$59.8 \%(0.587)$

$57.6 \%$

$64.6 \%(0.428)$

$57.1 \%$

$55.4 \%(0.396)$

$61.7 \%$

$58.8 \%(0.723)$

\begin{tabular}{|c|c|c|}
\hline Characteristic & $\begin{array}{l}\text { 5-year overall survival } \\
\text { ( } p \text {-value) }\end{array}$ & $\begin{array}{l}\text { 5-year recurrence- } \\
\text { free survival }\end{array}$ \\
\hline \multicolumn{3}{|c|}{ Lymphatic invasion } \\
\hline Yes & $50 \%(0.948)$ & $50 \%(0.752)$ \\
\hline No & $51.2 \%$ & $59.1 \%$ \\
\hline \multicolumn{3}{|l|}{ Invasion depth } \\
\hline$\geq 11 \mathrm{~mm}$ & $52.1 \%(0.432)$ & $69.2 \%(0.177)$ \\
\hline$<11 \mathrm{~mm}$ & $42.9 \%$ & $57.1 \%$ \\
\hline \multicolumn{3}{|l|}{ RT technique } \\
\hline Other & $47.2 \%(0.623)$ & $51.7 \%(0.489)$ \\
\hline IMRT & $56.1 \%$ & $78.3 \%$ \\
\hline \multicolumn{3}{|l|}{ RT duration } \\
\hline$>8$ weeks & $28.6 \%(0.07)$ & $28.6 \%(0.063)$ \\
\hline$\leq 8$ weeks & $53.7 \%$ & $62.3 \%$ \\
\hline \multicolumn{3}{|c|}{ Time between OP \& RT } \\
\hline$>6$ weeks & $42 \%(0.192)$ & $48.2 \%(0.38)$ \\
\hline$\leq 6$ weeks & $57 \%$ & $65.5 \%$ \\
\hline \multicolumn{3}{|l|}{ RT Dose } \\
\hline$<6600$ cGy & $39.2 \%(0.065)$ & $50.8 \%(0.191)$ \\
\hline 6600 cGy & $73.9 \%$ & $73.7 \%$ \\
\hline \multicolumn{3}{|c|}{ Concurrent chemotherapy } \\
\hline No & $35.3 \%(0.018)^{*}$ & $426 \%(0.009)^{*}$ \\
\hline Yes & $67.2 \%$ & $75.4 \%$ \\
\hline
\end{tabular}

$59.2 \%$

$60 \%(0.785)$

$57 \%$
Table 3 Overall and recurrence-free survival according to patient characteristics and treatment variables (Continued)

*Statistically significant in the multivariate analysis, $p<0.05$

Abbreviations: $R T$ radiotherapy, IMRT intensity-modulated radiotherapy,

$O P$ operation

oral cavity cancer is still controversial. Chung et al. showed that HPV status correlated with prognosis only in oropharyngeal cancer [19]. Other studies focusing on OSCC and HPV status used different detection method and both better and worse prognosis correlated HPV status were reported $[20,21]$. Therefore, the result of current study should not be affected significantly without data of HPV infection.

When used with concurrent chemotherapy, other treatment factors did not alter the treatment result. However, CCRT was more toxic to patients. In the current study, CCRT resulted in a mortality rate of $2.8 \%$, which was comparable to the rate in postoperative CCRT arms in randomized trials $[4,5]$. However, less toxic but equally effective regimens should be investigated. In a randomized trial of head and neck cancer, adding cetuximab to radiotherapy reduced locoregional recurrence and mortality without increasing toxicity [22]. Unfortunately, no published results have shown that cetuximab has efficacy equal to or better than that of cisplatin. One retrospective study even reported that cetuximab is inferior to cisplatin with respect to tumor 
Table 4 Multivariate analysis of overall and recurrence-free survival according to patient characteristics and treatment variables

\begin{tabular}{lllll}
\hline Characteristic & $\begin{array}{l}\text { Overall survival } \\
p \text {-value }\end{array}$ & $\begin{array}{l}\text { Overall survival HR } \\
(95 \% \text { Cl) }\end{array}$ & $\begin{array}{l}\text { Recurrence-free } \\
\text { survival } p \text {-value }\end{array}$ & $\begin{array}{l}\text { Recurrence-free } \\
\text { survival HR (95\% Cl) }\end{array}$ \\
\hline Chemotherapy & 0.017 & $0.426(0.212-0.858)$ & 0.002 & $0.248(0.103-0.596)$ \\
Betel quid & 0.004 & $3.951(1.567-9.966)$ & NS & NS \\
Anemia & 0.003 & $3.1(1.488-6.461)$ & NS & NS \\
Pathological T4 & NS & NS & 0.016 & $0.355(0.153-0.826)$ \\
Invasion depth $\geq 11 \mathrm{~mm}$ & 0.007 & $0.187(0.055-0.632)$ & $<0.001$ & $0.077(0.02-0.303)$ \\
Interval between surgery and PORT & NS & NS & 0.003 & $3.872(1.582-9.474)$ \\
\hline Abb
\end{tabular}

Abbreviation: $H R$ hazard ratio, $\mathrm{Cl}$ confidence interval, PORT postoperative radiotherapy, NS not significant

control and survival [23]. Another phase II randomized trial showed that, compared to cisplatin, cetuximab concomitant to RT lowered compliance and increased acute toxicity rates [24]. Although there is no study directly comparing cetuximab and cisplatin concomitant to postoperative RT, one randomized trial has approved that adding Cetuximab to cisplatin-based CCRT did not improve the treatment result [25]. That may also imply that Cetuximab is not effective in combination with CCRT. Before the efficacy of Cetuximab was approved by randomized trials, replacing cisplatin with cetuximab should be avoided.

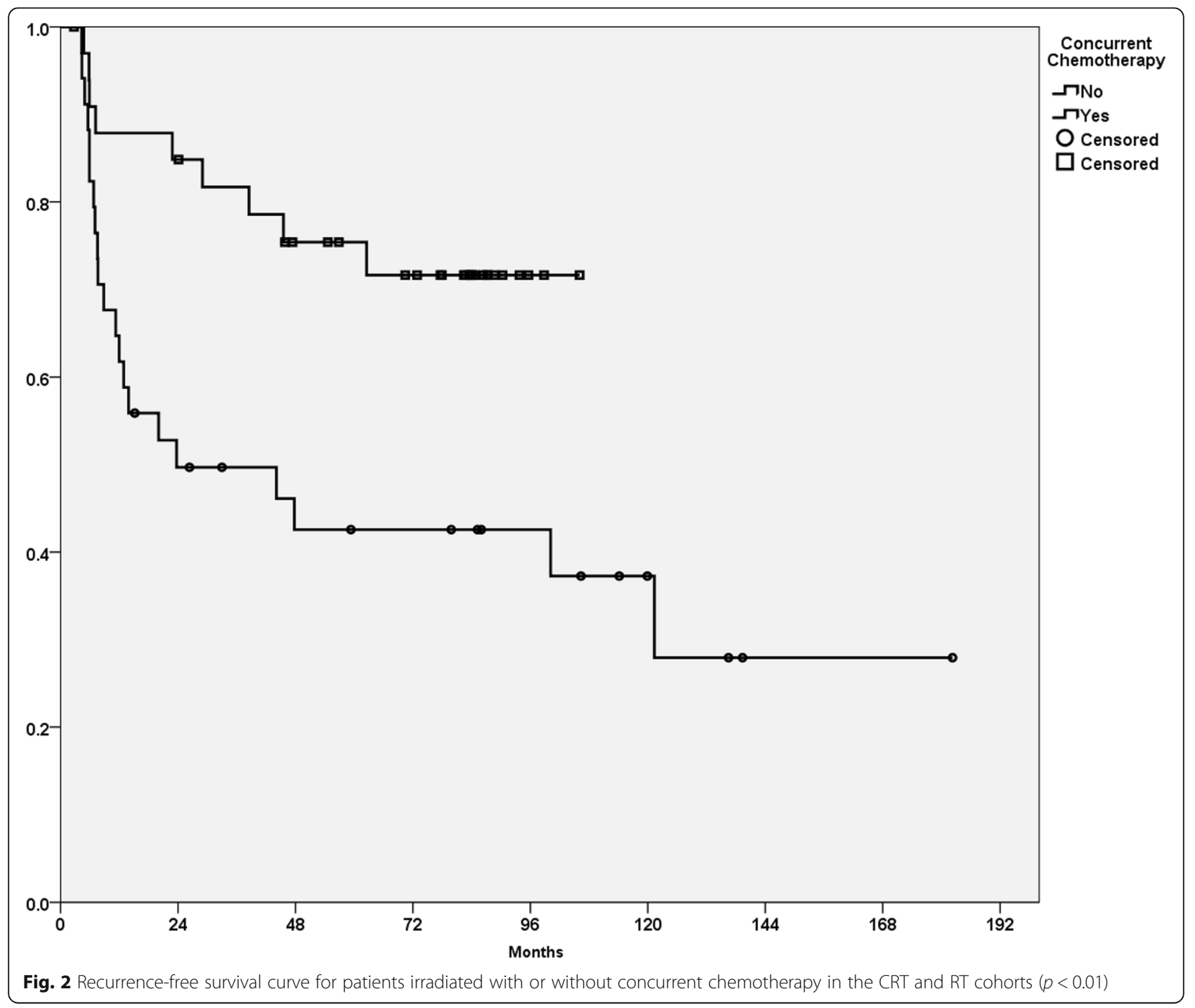




\section{Conclusion}

For patients with 3 or more minor risk factors, postoperative CCRT reduced the risk of tumor recurrence and increased OS compared with those in both the RT cohort and patients who refused chemotherapy in the CCRT group. The presence of three or more minor risk factors should be considered an indication for postoperative CCRT. A prospective, randomized trial may provide more unbiased evidence.

\section{Abbreviation}

3DCRT: 3-dimensional conformal radiation therapy; AJCC: American Joint Committee on Cancer; CCRT: Concurrent chemoradiation; Gy: Gray; HPV: Human papillomavirus; IMRT: Intensity modulation radiation therapy; MV: Megavoltage; OS: Overall survival; OSCC: Oral squamous cell carcinoma; PORT: Postoperative radiotherapy; RFS: Recurrence-free survival; RT: Radiotherapy

\section{Acknowledgements}

We would like to thank the cancer registry group of Chang Gung Memorial Hospital for their invaluable help of data collection and other support.

\section{Funding}

This work was supported by grants NMRPG386453 from the National Science Council in Taiwan and CMRPG1B0101 from the Chang Gung Memorial Hospital in Taiwan.

\section{Availability of data and materials}

The dataset from cancer registry can only be acquired under the permission of Chang Gung Memorial Hospital. Therefore, we are not able to release the clinical data of this study.

\section{Authors' contributions}

KHF, YCC, and JTC provided data collection, data analysis, data interpretation and manuscript writing. CYL, CJK, LYL, SFH, CTL, SHN, and HMW provided data collection and data analysis. All authors read and approved the final manuscript.

\section{Ethics approval and consent to participate}

This retrospective study was part of a clinical study approved by the institutional review board (97-0402B).

\section{Consent for publication}

Not applicable.

\section{Competing interests}

The authors declare that they have no competing interests.

\section{Publisher's Note}

Springer Nature remains neutral with regard to jurisdictional claims in published maps and institutional affiliations.

\section{Author details}

${ }^{1}$ Department of Radiation Oncology, Chang Gung Memorial Hospital at LinKou, Taoyuan, Taiwan. ${ }^{2}$ Departments of Radiation Oncology, Chang Gung Memorial Hospital at Keelung, Keelung, Taiwan. ${ }^{3}$ Department of Internal Medicine, Division of Hematology/Oncology, Chang Gung Memorial Hospital at LinKou, Taoyuan, Taiwan. ${ }^{4}$ Departments of Otolaryncology-Head and Neck Surgery, Chang Gung Memorial Hospital at LinKou, Taoyuan, Taiwan. ${ }^{5}$ Departments of Pathology, Chang Gung Memorial Hospital at LinKou, Taoyuan, Taiwan. ${ }^{6}$ Departments of Diagnostic Radiology, Chang Gung Memorial Hospital at LinKou, Taoyuan, Taiwan. ${ }^{7}$ Graduate Institute of Clinical Medical Science, School of Medicine, Chang Gung University, Taoyuan, Taiwan. ${ }^{8}$ Department of Medicine, School of Medicine, Chang Gung University, Taoyuan, Taiwan. ${ }^{9}$ Department of Radiation Oncology, Xiamen Chang Gung Memorial Hospital, Xiamen, Fujian, China.
Received: 11 April 2017 Accepted: 30 October 2017

Published online: 22 November 2017

\section{References}

1. Fletcher GH, Evers WT. Radiotherapeutic management of surgical recurrences and postoperative residuals in tumors of the head and neck. Radiology. 1970;95(1):185-8.

2. Kramer S, Gelber RD, Snow JB, Marcial VA, Lowry LD, Davis LW, Chandler R. Combined radiation therapy and surgery in the management of advanced head and neck cancer: final report of study $73-03$ of the radiation therapy oncology group. Head Neck Surg. 1987;10(1):19-30.

3. Dimery IW, Hong WK. Overview of combined modality therapies for head and neck cancer. J Natl Cancer Inst. 1993:85(2):95-111.

4. Bernier J, Domenge C, Ozsahin M, Matuszewska K, Lefebvre JL, Greiner RH, Giralt J, Maingon P, Rolland F, Bolla M, et al. Postoperative irradiation with or without concomitant chemotherapy for locally advanced head and neck cancer. N Engl J Med. 2004;350(19):1945-52.

5. Cooper JS, Pajak TF, Forastiere AA, Jacobs J, Campbell BH, Saxman SB, Kish JA, Kim HE, Cmelak AJ, Rotman M, et al. Postoperative concurrent radiotherapy and chemotherapy for high-risk squamous-cell carcinoma of the head and neck. N Engl J Med. 2004;350(19):1937-44.

6. Fan $\mathrm{KH}$, Wang HM, Kang CJ, Lee LY, Huang SF, Lin CY, Chen EY, Chen $\mathrm{H}$, Liao CT, Chang JT. Treatment results of postoperative radiotherapy on squamous cell carcinoma of the oral cavity: coexistence of multiple minor risk factors results in higher recurrence rates. Int J Radiat Oncol Biol Phys. 2010:77(4):1024-9.

7. Parsons JT, Mendenhall WM, Stringer SP, Cassisi NJ, Million RR. An analysis of factors influencing the outcome of postoperative irradiation for squamous cell carcinoma of the oral cavity. Int J Radiat Oncol Biol Phys. 1997;39(1):137-48.

8. Edge SBBD, Compton CC, Fritz AG, Greene FL, Trotti A. AJCC cancer staging manual. 7th ed. New York: Springer; 2010

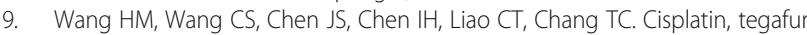
and leucovorin: a moderately effective and minimally toxic outpatient neoadjuvant chemotherapy for locally advanced squamous cell carcinoma of the head and neck. Cancer. 2002;94(11):2989-95.

10. Bachaud JM, Cohen-Jonathan E, Alzieu C, David JM, Serrano E, Daly-Schveitzer $\mathrm{N}$. Combined postoperative radiotherapy and weekly cisplatin infusion for locally advanced head and neck carcinoma: final report of a randomized trial. Int J Radiat Oncol Biol Phys. 1996;36(5):999-1004.

11. Gross ND, Patel SG, Carvalho AL, Chu PY, Kowalski LP, Boyle JO, Shah JP, Kattan MW. Nomogram for deciding adjuvant treatment after surgery for oral cavity squamous cell carcinoma. Head Neck. 2008;30(10):1352-60.

12. Hinerman RW, Mendenhall WM, Morris CG, Amdur RJ, Werning JW, Villaret DB. Postoperative irradiation for squamous cell carcinoma of the oral cavity: 35-year experience. Head Neck. 2004;26(11):984-94.

13. Peters $\sqcup$, Goepfert H, Ang KK, Byers RM, Maor MH, Guillamondegui O, Morrison WH, Weber RS, Garden AS, Frankenthaler RA, et al. Evaluation of the dose for postoperative radiation therapy of head and neck cancer: first report of a prospective randomized trial. Int J Radiat Oncol Biol Phys. 1993;26(1):3-11.

14. Pignon JP, le Maitre A, Maillard E, Bourhis J, Group M-NC: Meta-analysis of chemotherapy in head and neck cancer (MACH-NC): an update on 93 randomised trials and 17,346 patients. Radiotherapy Oncol 2009, 92(1):4-14.

15. Ko YC, Huang YL, Lee CH, Chen MJ, Lin LM, Tsai CC. Betel quid chewing, cigarette smoking and alcohol consumption related to oral cancer in Taiwan. J. Oral Pathol. Med. 1995:24(10):450-3.

16. Peng G, Wang T, Yang KY, Zhang S, Zhang T, Li Q, Han J, Wu G. A prospective, randomized study comparing outcomes and toxicities of intensity-modulated radiotherapy vs. conventional two-dimensional radiotherapy for the treatment of nasopharyngeal carcinoma. Radiother Oncol. 2012;104(3):286-93.

17. Nutting CM, Morden JP, Harrington KJ, Urbano TG, Bhide SA, Clark C, Miles EA, Miah AB, Newbold K, Tanay M, et al. Parotid-sparing intensity modulated versus conventional radiotherapy in head and neck cancer (PARSPORT): a phase 3 multicentre randomised controlled trial. Lancet Oncol. 2011;12(2):127-36.

18. Gupta T, Agarwal J, Jain S, Phurailatpam R, Kannan S, Ghosh-Laskar S, Murthy V, Budrukkar A, Dinshaw K, Prabhash K, et al. Three-dimensional conformal radiotherapy (3D-CRT) versus intensity modulated radiation therapy (IMRT) in squamous cell carcinoma of the head and neck: a randomized controlled trial. Radiother Oncol. 2012;104(3):343-8.

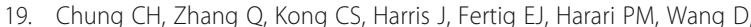
Redmond KP, Shenouda G, Trotti A, et al. p16 protein expression and 
human papillomavirus status as prognostic biomarkers of nonoropharyngeal head and neck squamous cell carcinoma. J Clin Oncol. 2014;32(35):3930-8.

20. Chen YW, Kao SY, Yang MH. Analysis of p16 (INK4A) expression of oral squamous cell carcinomas in Taiwan: prognostic correlation without relevance to betel quid consumption. J Surg Oncol. 2012;106(2):149-54.

21. Lee LA, Huang CG, Liao CT, Lee LY, Hsueh C, Chen TC, Lin CY, Fan KH, Wang HM, Huang SF, et al. Human papillomavirus-16 infection in advanced oral cavity cancer patients is related to an increased risk of distant metastases and poor survival. PLoS One. 2012;7(7):e40767.

22. Bonner JA, Harari PM, Giralt J, Azarnia N, Shin DM, Cohen RB, Jones CU, Sur R, Raben D, Jassem J, et al. Radiotherapy plus cetuximab for squamous-cell carcinoma of the head and neck. N Engl J Med. 2006;354(6):567-78.

23. Koutcher L, Sherman E, Fury M, Wolden S, Zhang Z, Mo Q, Stewart L, Schupak K, Gelblum D, Wong R, et al. Concurrent cisplatin and radiation versus cetuximab and radiation for locally advanced head-and-neck cancer. Int J Radiat Oncol Biol Phys. 2011;81(4):915-22.

24. Magrini SM, Buglione M, Corvo R, Pirtoli L, Paiar F, Ponticelli P, Petrucci A, Bacigalupo A, Crociani M, Lastrucci L, et al. Cetuximab and radiotherapy versus Cisplatin and radiotherapy for locally advanced head and neck cancer: a randomized phase II trial. J Clin Oncol. 2016;34(5):427-35.

25. Ang KK, Zhang Q, Rosenthal DI, Nguyen-Tan PF, Sherman EJ, Weber RS, Galvin JM, Bonner JA, Harris J, El-Naggar AK, et al. Randomized phase III trial of concurrent accelerated radiation plus cisplatin with or without cetuximab for stage III to IV head and neck carcinoma: RTOG 0522. J Clin Oncol. 2014;32(27):2940-50

\section{Submit your next manuscript to BioMed Central and we will help you at every step:}

- We accept pre-submission inquiries

- Our selector tool helps you to find the most relevant journal

- We provide round the clock customer support

- Convenient online submission

- Thorough peer review

- Inclusion in PubMed and all major indexing services

- Maximum visibility for your research

Submit your manuscript at www.biomedcentral.com/submit

) Biomed Central 